\title{
O IMPACTO DAS REFORMAS DA ADMINISTRAÇÃO PÚBLICA BRASILEIRA NA REGULAÇÃO CONTABILÍSTIÇA DO SETOR
}

\author{
Renato Pereira Monteiro ${ }^{1}$ \\ Cleber Augusto Pereira ${ }^{2}$ \\ Neimar Sousa Pinto Pereira ${ }^{3}$
}

\section{RESUMO}

O objetivo deste estudo é descrever como as reformas da administração pública brasileira ao longo do último século impactaram nas mudanças e inovações da contabilidade aplicada ao setor. O estudo é relevante pois permite entender o processo de convergência das normas de contabilidade a um novo padrão não só de regulação internacional, mas como de adaptação a uma nova realidade do setor público. Para tal realizou-se ampla pesquisa bibliográfica que identificou o contexto e características principais de cada período, nomeadamente a administração patrimonialista, a burocrática e a nova gestão pública, também conhecida como administração pública gerencial (NGP). Apresentasse o estágio atual e a inovações comentadas da contabilidade pública no Brasil. Ao final do estudo, constou-se que existe relação entre alguns preceitos da NGP como o foco no resultado, na eficiência, eficácia e efetividade, flexibilização da gestão, transparência e controle social e aumento da responsabilização com os novos e relevantes objetivos da contabilidade pública, em especial, apoio ao processo decisório, instrumentalização do controle social e adequada prestação de contas. Estes objetivos, decorrentes dos preceitos desdobram-se em normas específicas que foram mapeadas e relacionadas com cada objetivo.

Palavras-chave: Contabilidade Pública. Nova Gestão Pública. Reforma Contábil. NBCASP.

\section{INTRODUÇÃO}

No decorrer das últimas décadas a contabilidade púbica brasileira tem passado por diversas modificações, decorrentes muitas delas do processo de reformas do setor público, da criação de novos valores institucionais, das novas demandas sociais, da imposição de órgãos de controle e de um novo contexto de econômico e social.

As reformas demonstram que o setor público precisou evoluir para acompanhar a demanda da sociedade por maior controle, transparência, eficiência e eficácia na gestão dos recursos públicos. Com esse efeito, coube a contabilidade pública, conhecida atualmente como Contabilidade Aplicada ao Setor Público (CASP) adaptar-se e acompanhar estas

\footnotetext{
${ }^{1}$ Doutorando em Contabilidade pela Universidade de Aveiro e Universidade do Minho em Portugal, Mestre em Contabilidade pela UNISINOS, São Leopoldo-RS (2012), Bacharel em Ciências Contábeis pelo Centro Universitário La Salle (2004), Contador do IFRS - Campus Porto Alegre. renatomonteir@gmail.com

${ }^{2}$ Doutorando em Ciência da Administração pela Universidade do Minho em Portugal, Mestre em Inteligência Artificial pela UFMA, Maranhão (2010), Bacharel em Ciências Contábeis pela Universidade CEUMA, Maranhão (1999), Professor Assistente com Dedicação Exclusiva na UFMA, Maranhão. kcleber@ gmail.com

${ }^{3}$ Doutoranda em Ciências Empresariais pela Universidade do Minho em Portugal, Mestre em Administração e Controladoria pela UFC, Ceará (2010), Bacharel em Ciências Contábeis pela Universidade CEUMA, Maranhão (2005), Professora Assistente com Dedicação Exclusiva na UFMA, Maranhão. neimar.anjo@ gmail.com 
mudanças para ser útil a sociedade, evidenciando as informações necessárias ao controle social e a accountability.

O setor público brasileiro, passou por três fases distintas que podem ser considerados como estágios da administração pública, começando na chamada era Patrimonialista, depois a Burocrática, e no seu estágio atual a Nova Gestão Pública (NGP). Este estudo tem como objetivo descrever como as reformas do setor público impactaram nas mudanças da CASP, apoiadas em um processo de convergência internacional das normas.

O estudo é relevante pois permite entender o processo de criação e de convergência das normas de contabilidade a um novo padrão não só de regulação internacional, mas como de adaptação a uma nova realidade do setor público em que as demandas sociais e administrativas por informação mudaram.

O estudo está organizado apresentando incialmente o que é a administração Pública no contexto brasileiro, descrevendo os estágios pelos quais passou, a seguir evidenciasse o conjunto de normativos criados. A seguir apresenta-se a metodologia do estudo, trata-se das características de padronização, finalizando uma abordagem sobre o impacto da NGP na contabilidade pública e com a conclusão do estudo.

\section{REFERENCIAL TEÓRICO}

\subsection{Administração Pública}

Como forma de dar sustentação ao estudo e ampliar o entendimento que se tem sobre a Administração Pública em seu conjunto, faz-se pertinente entender o seu significado e funcionamento. O termo Administração Pública quando utilizado em letras maiúsculas representa o Estado agindo por meio de suas funções e exercendo atividades administrativas. Meirelles (1989, p. 78-79) define a diferença entre a Administração Privada e a Pública que é apresentada no Quadro 1.

Quadro 1 - Administração Privada e Administração Pública

\begin{tabular}{|c|l|}
\hline Administrar & $\begin{array}{l}\text { Em sentido lato é gerir interesses, conforme a lei, a moral e a finalidade dos bens } \\
\text { entregues à guarda e conservação alheia. }\end{array}$ \\
\hline $\begin{array}{c}\text { Administração } \\
\text { Particular }\end{array}$ & $\begin{array}{l}\text { Gerir interesses, conforme a lei, a moral e a finalidade dos bens } \\
\text { PARTICULARES entregues à guarda e conservação alheia, envolve interesses } \\
\text { particulares. }\end{array}$ \\
\hline Administração Pública & $\begin{array}{l}\text { Gerir interesses, conforme a lei, a moral e a finalidade dos bens PÚBLICOS } \\
\text { entregues à guarda e conservação alheia, envolve interesses públicos. Neste } \\
\text { sentido, entende-se como gestão de bens e interesses qualificados da comunidade } \\
\text { no âmbito federal, estadual ou municipal, segundo os preceitos do Direito e da } \\
\text { Moral, visando ao bem comum. }\end{array}$ \\
\hline
\end{tabular}

Fonte: Elaborado com base em Meirelles (1989). 
No entender de Meirelles (1989), a Administração Pública é o conjunto de ações do Estado no objetivo de gerir, cumprindo as leis, a moral e a ética, além dos interesses da sociedade, sempre respeitando os interesses da coletividade. Enfim, são as ações que o Estado tem o dever e o direito de praticar.

A Administração Pública no Brasil deve obedecer aos princípios da legalidade, impessoalidade, moralidade, publicidade e eficiência. Deve ser exercida por órgãos da administração direta, pelos órgãos da administração indireta e pelos órgãos da administração delegada. Tais princípios, norteadores da Administração Pública, são apresentados no Quadro 2.

Quadro 2 - Princípios da Administração Pública

\begin{tabular}{|c|l|}
\hline Princípio & Entendimento \\
\hline Legalidade & $\begin{array}{l}\text { Estrita obediência à lei; nenhum resultado poderá ser considerado bom, nenhuma gestão } \\
\text { poderá ser reconhecida como de excelência se executada à revelia da lei. }\end{array}$ \\
\hline Impessoalidade & $\begin{array}{l}\text { Não fazer acepção de pessoas. O tratamento diferenciado restringe-se apenas aos casos } \\
\text { previstos em lei. A cortesia, a rapidez no atendimento e a confiabilidade são requisitos } \\
\text { dos serviços públicos e devem ser agregados a todos os usuários indistintamente. Em se } \\
\text { tratando de organização pública, todos os seus usuários devem ser pessoas muito } \\
\text { importantes. }\end{array}$ \\
\hline Moralidade & Pautar a gestão pública por um código moral. \\
\hline Publicidade & $\begin{array}{l}\text { Ser transparente, dar publicidade aos fatos e aos dados. É uma forma eficaz de indução } \\
\text { do controle social. }\end{array}$ \\
\hline Eficiência & $\begin{array}{l}\text { Fazer o que precisa ser feito com o máximo de qualidade ao menor custo possível. Não } \\
\text { se trata de redução de custos de qualquer maneira, mas de buscar a melhor relação entre } \\
\text { qualidade do serviço e qualidade do gasto. }\end{array}$ \\
\hline
\end{tabular}

Fonte: Lima (2009).

Segundo Sothe e Scarpin (2009, p. 28) dentre os princípios estabelecidos pela constituição "a eficiência apresenta-se como fundamental para o cumprimento das funções atribuídas à administração pública". Também, nos últimos anos, a publicidade dos atos públicos ganhou relevância com o advento de meios mais abrangentes de comunicação, como a rede mundial de computadores (CASTRO, 2011).

Percebe-se que a Administração Pública é o agente responsável por gerir os bens públicos no Brasil e deve realizar estas ações com fundamento nos Princípios Norteadores estabelecidos na Constituição Federal. No Brasil, esta administração passou por três períodos bem característicos e que não são excludentes entre si. Estes períodos ficaram conhecidos como o da administração patrimonialista, da burocrática e da gerencial. As características de um período anterior acabaram por contribuir para a formação do período seguinte (BRESSER-PEREIRA, 1996). Tais períodos são tratados na sequência. 


\subsection{Administração Pública Patrimonialista}

O patrimonialismo, como ficou conhecido o período da administração pública patrimonialista, era a forma de atuação dos detentores de poder na época das monarquias, característica dos Estados absolutistas europeus do século XVIII. Neste modelo, o patrimônio público e o privado eram confundidos. Conforme Bresser-Pereira (1996, p. 3), neste tipo de administração, “o Estado era entendido como propriedade do rei”. O autor ainda relata que a corrupção, o empreguismo e o nepotismo eram regras neste tipo de administração. A ética e a legalidade estavam em um segundo plano neste modelo de gestão.

Também para Campante (2003) o patrimonialismo é personalista e tende a desprezar a distinção entre as esferas privadas e públicas. Afirma que o poder pessoal e o interesse particular imperam nas decisões. A mesma visão é apontada por Martins (1997, p. 3) quando destaca que na época do Patrimonialismo prevalecia "o paternalismo e o nepotismo que empregava os inúteis letrados, na prática do bacharelismo cujos critérios de seleção e provimento oscilavam entre o status, o parentesco e o favoritismo". Verifica-se, segundo a ótica de Martins (1997), a falta de profissionalismo da gestão pública neste período.

A administração pública, nesta fase, era dominada por grupos que visavam à manutenção de seu poder, a garantia de seus interesses e a proteção mútua de seus pares. Esses grupos se aglutinavam no aparato estatal para defender seus interesses, em busca de recursos públicos para sua sobrevivência, construindo uma rede de apoio de lealdade política e preservação de lideranças. Esta face do patrimonialismo pode ser sentida ainda nos dias atuais (ABRUCIO, 2007).

Motta (2007) descreve que a gestão dos recursos públicos era voltada para atender demandas e necessidades de pequenos grupos particulares, aplicada na troca de favores, ficando em segundo plano o uso destes nas demandas e necessidades reais da comunidade, no referido período. Neste contexto, uma gestão econômica direcionada aos interesses da sociedade parece que inexistia neste período da administração pública nacional.

Costa (2008, p. 846) afirma que a reforma administrativa do Estado Novo foi o primeiro passo para superar o patrimonialismo classificando como "uma ação deliberada e ambiciosa no sentido da burocratização do Estado brasileiro.”. Na tentativa de combater as práticas de pessoalidade, a descentralização inadequada da gestão, a relação imoral entre o público e o privado surgiu a Administração Pública Burocrática que visava entre outras coisas estabelecer o sistema de mérito, separação entre o público e o privado, enfim construir uma 
administração mais racional e eficiente para o crescimento e desenvolvimento do país (COSTA, 2008).

\subsection{Administração Pública Burocrática}

O segundo período pelo qual passou a administração pública brasileira foi o modelo de gestão burocrática, implantado no Brasil, durante o regime militar, nos anos 60, na tentativa de extinguir o modelo patrimonialista e avançar na profissionalização do serviço público (BRESSER-PEREIRA, 1996). O modelo burocrático foi muito difundido no século XX, uma vez o Estado começou a exercer um papel social diferenciado, destinado a atender as demandas da sociedade por saúde, educação, segurança, cultura, previdência e pesquisa científica.

Secchi (2009, p.350) destaca que o modelo burocrático weberiano é atribuído a Max Weber "por que o sociólogo alemão analisou e sintetizou suas principais características". Ficou conhecido também na literatura inglesa como a progressive public administration, que induziu mudanças no setor público dos Estados Unidos, no século XIX e XX. Secchi (2009, p. 350) ainda afirma que “desde o século XVI o modelo burocrático já era bastante difundido nas administrações públicas, nas organizações religiosas e militares, especialmente na Europa".

No Brasil, a burocratização de seu sistema administrativo ocorreu de forma lenta e superficial nos seus primeiros 100 anos de história independente, mas teve seu auge e aceleração na Revolução de 1930 (COSTA, 2008). A estrutura estatal vigente estava corroída pelos vícios do patrimonialismo, assim, o Governo de Getúlio Vargas deu início tendo como objetivo: (1) estabelecer mecanismos de controle da crise econômica, resultante dos efeitos da Grande Depressão, iniciada em 1929, e subsidiariamente promover uma alavancagem industrial; e (2) promover a racionalização burocrática do serviço público, por meio da padronização, normatização e implantação de mecanismos de controle, notadamente nas áreas de pessoal, material e finanças (COSTA, 2008).

Uma das características deste modelo retratadas por Secchi $(2009$, p. 351) é a impessoalidade das relações dos membros da organização, inclusive com o ambiente externo:

A impessoalidade prescreve que a relação entre os membros da organização e entre a organização e o ambiente externo está baseada em funções e linhas de autoridade claras. O chefe ou diretor de um setor ou departamento tem a autoridade e responsabilidade para decidir e comunicar sua decisão. $\mathrm{O}$ chefe ou diretor é a pessoa que formalmente representa a organização. Ainda mais importante, a impessoalidade implica que as posições hierárquicas pertencem à organização, e não às pessoas que 
a estão ocupando. Isso ajuda a evitar a apropriação individual do poder, prestígio, e outros tipos de benefícios, a partir do momento que o indivíduo deixa sua função ou a organização.

Alguns dos problemas da administração burocrática considerados por Bliska e Vicente (2001) foram: (1) desperdício de recursos públicos; (2) desperdício das capacidades e competências dos servidores, com a inibição de seu potencial criativo; (3) distância entre a decisão e a ação, em prejuízo ao atendimento dos cidadãos.

Com efeito, o Estado foi estimulando o desenvolvimento de novos meios de gestão, dado que a administração pública burocrática não comprovou ser o sinônimo de eficiência que se esperava. Verificou-se, com o passar dos anos, que ela não garantia rapidez, qualidade e custo baixo dos serviços públicos, ficando conhecida como lenta e cara, além de pouco atender as demandas da população (BRESSER-PEREIRA, 1996).

A busca pela nova configuração da gestão do setor público repercutiu na forma do movimento chamado Nova Gestão Pública, que surge como resposta às falhas do modelo burocrático-weberiano de gestão do Estado, que estava superado, tratado por Giacomo (2005, p.159) como "caracterizado pelo aumento da máquina pública pela falta de qualidade e ineficiência dos serviços".

\subsection{Administração Pública Gerencial - Nova Gestão Pública (NGP)}

Graef (2010) enfatiza que, após a Constituição Federal de 1988, com as primeiras eleições diretas, o governo vigente à época promoveu uma série de reformas, contemplando: (1) abertura da economia ao capital externo; (2) desregulamentação do mercado; (3) desestatização; (4) abertura do mercado nacional; (5) tentativas de controle do processo inflacionário; (6) redução do tamanho do Estado; (7) uma política de redução do gasto público. Estas reformas colaboraram para o surgimento desta nova administração no âmbito nacional.

Segundo Bliska e Vicente (2001), um modelo de administração gerencial deve estar centrado na efetividade dos resultados da organização, nas ações do corpo funcional e diretivo, que devem fortalecer o cumprimento da missão institucional e, ainda, na valorização dos recursos públicos aplicados em cada atividade. Conforme destaca Lima (2009), desde 1995, os poderes executivos dos Estados e da União têm desenvolvido inovações em termos de gestão, alicerçada em dois pontos principais: (1) tornar a gestão pública mais voltada para o cidadão e para a sociedade do que para a burocracia; (2) aproximar a gestão pública das características da gestão contemporânea.

\begin{tabular}{lr}
\hline Volume 3, Número 6 & Revista UNEMAT de Contabilidade \\
Jul./Dez. 2014 & UNEMAT
\end{tabular}


Na NGP, o cidadão passa a ser considerado como cliente. Objetiva-se atingir melhores níveis de eficiência e eficácia, com base na ética e transparência, com fundamento também na responsabilidade fiscal. Para Rezende (2002, p. 112), um dos relevantes fatores das recentes mudanças nos modelos de gestão pública centra-se na "necessidade contínua de lidar com problemas crônicos de eficiência, efetividade e eficácia na administração pública". Nas últimas décadas do século XX, mais especificamente nos anos 80, desencadearam-se em diversos países os debates sobre a gestão pública contemporânea, com base na necessidade do Estado desenvolver um novo papel devido às novas demandas sociais oriundas das recentes crises financeiras (anos 70), de acordo com Marini (2002).

Vivia-se um esgotamento do modelo burocrático vigente, que tinha entre suas características a baixa qualidade do serviço prestado aos cidadãos. Conforme afirma Marini (2002), este processo de gerar estratégias para o rompimento deste antigo modelo foi denominada de New Public Management - NPM. Com início na Grã-Bretanha, ficou conhecida no Brasil como Nova Gestão Pública - NGP. O novo modelo de gestão proposto tem entre seus objetivos eliminar ou substituir procedimentos burocráticos que contribuam para a ineficiência do setor público, bem como incentivar a adoção pelos governos locais de métodos bem sucedidos na iniciativa privada, como a terceirização de serviços. Um dos efeitos dessa adoção foi a exclusão de alguns cargos e das carreiras de poderes, como os de faxineira, motorista, porteiros e copeiros, substituídos por contratos de terceirização.

Hood (1995) classificou a NPM como um programa que consiste em aplicar, na esfera pública, conceitos e técnicas desenvolvidos com sucesso na iniciativa privada, para obter uma maior eficiência e efetividade na conquista dos objetivos das entidades públicas. Giacomo (2005, p. 160) afirma que a NGP, a qual denomina APG - Administração Pública Gerencial, também tem como característica a "utilização intensa das práticas gerenciais com ênfase na eficácia, sem, contudo, perder de vista a função eminentemente pública do aparelho estatal”. O autor apresenta como pontos chave da NGP: (1) a descentralização; (2) a delegação de autoridade; (3) um rígido controle sobre o desempenho; (4) a consideração da sociedade como consumidora.

Fabián (2010, p. 43-44) estabelece seis dimensões onde a NPM deve agir: (1) os governos devem se envolver com as funções mais importantes; (2) estrutura de serviço voltada e centrada no resultado organizacional; (3) os processos de gestão devem estar divididos de forma que cada etapa adicione valor à etapa anterior; (4) expansão da automação 
e informatização do setor público; (5) elementos competitivos devem ser aplicados ao setor público; e (6) gestão efetiva política e administrativamente.

$\mathrm{Na}$ América Latina, as mudanças no setor público também começaram a ocorrer de um modo geral. Marini (2002) apresenta um levantamento deste contexto em diversos países como Uruguai, Chile, Peru, Nicarágua, Argentina, Venezuela, Guatemala e México. Marini (2002) relata que, no Uruguai, as modificações iniciaram com medidas no sistema de seguridade social, na educação, no sistema político e na administração pública, principalmente, com alterações no orçamento público. Neste país, as reformas também estavam voltadas para a estrutura organizacional e o melhor atendimento dos usuários de serviços públicos.

No Chile, segundo Marini (2002), as mudanças tiveram por base o planejamento estratégico das ações de governo, além de acordos de modernização do Estado e tentativas de estabelecer indicadores e metodologias de avaliação de desempenho do setor público. Já no Peru as mudanças tinham como foco, além da melhoria da gestão como um todo, a construção de um Estado mais democrático, descentralizado e voltado para os serviços ao cidadão (MARINI, 2002).

Na Argentina, o movimento teve início em 1983, quando foi criada a Secretaria da Função Pública. Posteriormente, em 1999, foi criada a Subsecretaria de Gestão Pública que desenvolveu um plano de modernização do Estado visando à implantação de um moderno sistema de gerência pública, para os organismos da Administração Nacional (Marini, 2002). O Quadro 3 sintetiza alguns objetivos das reformas deste movimento pela reforma gerencial dos países da América Latina.

Quadros 3 - Objetivos da NPM em Países da América Latina

\begin{tabular}{|c|l|}
\hline Países & \multicolumn{1}{c|}{ Objetivos } \\
\hline Uruguai & $\begin{array}{l}\text { (1) Melhorar a eficiência, eficácia e impacto do gasto público (...); (2) Obter maior } \\
\text { transparência, maior competitividade e eficiência nas aquisições públicas (...); (3) Disponibilizar } \\
\text { informações sobre rendimentos dos funcionários públicos (...); (4) Aperfeiçoar as condições } \\
\text { objetivas de trabalho por meio da disponibilização de informações sobre horas trabalhadas dos } \\
\text { funcionários da Administração Central; (5) Implantar a administração eletrônica usando a } \\
\text { tecnologia (...); (6) Desregulamentar por intermédio da implementação de mudanças, visando à } \\
\text { redução de custos e à eliminação de restrições desnecessárias para cidadãos e empresas. }\end{array}$ \\
\hline Chile & $\begin{array}{l}\text { (1) econômica: orientada a fortalecer a capacidade reguladora do Estado a partir dos processos } \\
\text { de privatização; (2) política: caracterizada pela transição de um Estado autoritário e } \\
\text { centralizador na direção de um Estado democrático, participativo e descentralizado; (3) social: a } \\
\text { partir de mudanças de um modelo frágil de provimento direto dos serviços sociais para um novo } \\
\text { modelo que compartilha estas funções com o mercado e o terceiro setor. (4) gestão: orientada } \\
\text { para a introdução de uma nova gerência pública baseada na qualidade e em resultados em } \\
\text { substituição a uma burocracia formalista baseada somente na norma. }\end{array}$ \\
\hline Peru & $\begin{array}{l}\text { (1) a melhoria da prestação de serviços; (2) a criação de canais de participação cidadã; (3) } \\
\text { descentralização e desconcentração; (4) uma gestão pública transparente e com equilíbrio físcal }\end{array}$ \\
\hline
\end{tabular}




\begin{tabular}{|l|l|}
\hline & (5) a qualificação dos servidores. \\
\hline \multirow{3}{*}{ Argentina } & $\begin{array}{l}\text { (1) Transformações institucionais que tem entre suas características o compromisso com o } \\
\text { cidadão e a gestão por resultados; (2) Transformações horizontais que tem foco no } \\
\text { desenvolvimento do capital humano e na modernização dos sistemas administrativos. }\end{array}$ \\
\hline
\end{tabular}

Fonte: Elaborado com base em Marini (2002).

Os objetivos da NPM consolidam um novo panorama mundial de maior preocupação tanto de gestores como da sociedade em melhorar não só a imagem das instituições públicas como da gestão como um todo. Também visam incentivar o controle social por meio da instrumentalização de ferramentas de maior transparência e divulgação dos resultados e dos gastos públicos. Observando-se os objetivos da NPM, na América Latina, e a maneira como eles foram implantados, chama a atenção o alinhamento entre países como Uruguai, Chile e Peru nos aspectos norteadores da NPM voltados em especial para a redução de custos, aumento de eficiência e eficácia, ações de maior transparência e prestação de serviços de melhor qualidade. Nestes países, as mudanças são focadas não só nas suas estruturas internas, mas também dependem da participação ativa da própria sociedade para a conquista destes objetivos, como o maior controle e a efetiva transparência. Ao contrário da Argentina, que tem seus objetivos mais voltados para sua estrutura interna como qualificação do seu quadro funcional, mudanças na estrutura administrativa, assim como suas alterações, não tem um nível de incentivo à participação social como nos objetivos dos outros países apresentados no Quadro 3.

Conforme Sano e Abrucio (2008), as primeiras ideias de Nova Gestão Pública chegaram ao Brasil, no governo Fernando Henrique Cardoso, em 1995, com a criação do Ministério da Administração e Reforma do Estado (MARE). Marini (2002) destaca que também, em 1995, foi elaborado o Plano Diretor da Reforma do Aparelho do Estado. Este documento partia de um diagnóstico dos principais problemas da administração pública e propunha um novo modelo conceitual, dividido em quatro segmentos, conforme apresentado no Quadro 4.

Quadro 4 - Segmentos Característicos da Ação do Plano Diretor

\begin{tabular}{|c|l|}
\hline Segmento & \multicolumn{1}{c|}{ Orientação } \\
\hline Núcleo Estratégico & Definição de leis e de políticas públicas e cobrança de seu cumprimento. \\
\hline Atividades Exclusivas & As que são indelegáveis e para seu exercício é necessário poder de Estado. \\
\hline $\begin{array}{c}\text { Atividades não } \\
\text { Exclusivas }\end{array}$ & $\begin{array}{l}\text { Aquelas de alta relevância em que o Estado atua simultaneamente com outras } \\
\text { organizações privadas e do terceiro setor na prestação de serviços sociais. }\end{array}$ \\
\hline Produção de Bens e & $\begin{array}{l}\text { Correspondem ao setor de infraestrutura onde atuam as empresas, portanto, com } \\
\text { tendências à privatização. }\end{array}$ \\
\hline
\end{tabular}

Fonte: Elaborado com base em Marini (2002). 
Uma das características do Plano Diretor foi estabelecer que no segmento estratégico do setor público é fundamental que as decisões sejam cumpridas conforme programadas. A efetividade é considerada como mais relevante do que a eficiência. O núcleo estratégico é fundamental para o cumprimento das ações, mas esta verificação só é possível utilizando os preceitos da administração burocrática (controles e processos) com a gestão gerencial no que tange ao cumprimento de metas. Nos segmentos de atividades exclusivas e não exclusivas, a prioridade se concentra na qualidade dos serviços prestados e nos custos incorridos nestas atividades, primando-se pela eficiência das ações, buscando uma otimização entre a qualidade e o custo dos serviços colocados à disposição do público altamente relacionados à gestão gerencial (BRASIL, 1995).

No segmento da produção de bens e serviços, as empresas visam ao lucro mesmo que façam parte do aparelho do Estado. Este tipo de segmento deve possuir uma regulamentação rígida, pois, em muitos dos casos, fazem parte de monopólios. Como visam ao lucro estão focadas na administração gerencial. Destaca-se que a produção de bens e serviços com o uso do capital estatal só deve ser aplicado quando não existir capitais privados disponíveis (BRASIL, 1995). A NPM no Brasil, segundo Sano e Abrucio (2008), consiste em três mecanismos essenciais, conforme apresentado no Quadro 5:

Quadro 5 - Aspectos Principais da Nova Gestão Pública no Brasil

\begin{tabular}{|l|l|}
\hline $\begin{array}{l}\text { Administração voltada } \\
\text { para resultado }\end{array}$ & $\begin{array}{l}\text { A gestão deve estar baseada em metas, indicadores e formas que possibilitem a } \\
\text { cobrança dos gestores alicerçada na transparência das ações governamentais, que } \\
\text { permitam o controle maior dos cidadãos e o uso de outros instrumentos de } \\
\text { accountability. }\end{array}$ \\
\hline $\begin{array}{l}\text { Pluralidade } \\
\text { Governamental }\end{array}$ & $\begin{array}{l}\text { Pluralidade dos provedores de serviços públicos, possibilidade de estabelecer formas } \\
\text { contratuais de gestão em estruturas estatais e entes públicos não estatais. }\end{array}$ \\
\hline $\begin{array}{l}\text { Flexibilização da } \\
\begin{array}{l}\text { Gestão Burocrática e } \\
\text { aumento } \\
\text { responsabilização da }\end{array}\end{array}$ & Por meio do funcionamento efetivo dos mecanismos institucionais de controle. \\
\hline
\end{tabular}

Fonte: Elaborado com base em Sano e Abrucio (2008).

Os aspectos principais trazidos por Sano e Abrucio (2008) demonstram que a gestão deve estar voltada para cumprir metas aplicadas ao atendimento das necessidades da população por meio da prestação de serviços de qualidade e, ainda, para a prestação de contas por meio da transparência efetiva das ações de governo, além de ampliar a estrutura estatal por meio da chamada descentralização dos serviços, utilizando contratos de gestão e parcerias públicas. Por fim, a flexibilização dos mecanismos burocráticos com o maior rigor no controle institucional. 
Christensen e Laegrid (2006) apontam o surgimento de uma nova tendência de gestão no setor público, sendo uma segunda geração das reformas no setor, conhecido em inglês como whole-of-government approach, inicialmente, chamada de joined-up government $J U G$. Este tipo de administração tem sido a tendência em países onde surgiu a NPM como o Reino Unido, Austrália e Nova Zelândia. Os mesmos autores afirmam que este conceito foi introduzido inicialmente no governo de Tony Blair, em 1997, no Reino Unido, tendo como principal objetivo um melhor controle dos limites de ações do setor público, nos níveis administrativos e na área política. Conforme estes autores, as iniciativas para a Totalidade do Governo - TG, como ficou conhecida no Brasil, são reações às experiências negativas das reformas trazidas pela NPM, como a ineficiência no processo de delegação de serviços públicos e o excesso de divisão das organizações especializadas que prejudica o controle e a efetividade dos serviços.

As razões elencadas por Christensen e Laegrid (2006) para esta nova fase da gestão pública consistem: (1) no excesso de cargos e funções especializados sobrepostos; (2) em autoridades centradas em si mesmas; (3) na falta de cooperação e coordenação entre os órgãos; (4) na dificuldade de atingir a eficiência e a eficácia.

As fases apresentadas da gestão pública remetem a um novo momento da contabilidade pública brasileira, tendo por base principalmente as filosofias da NPM e o movimento de harmonização das normas contábeis a padrões internacionais (CASTRO, 2011). Como efeito, a contabilidade pública deve desempenhar o seu verdadeiro papel, não só acompanhando o patrimônio público, mas sendo a responsável por um leque de informações capazes de suprir os gestores para a tomada de decisão, como indicado no conceito de Contabilidade Aplicada ao Setor Público da Resolução no 1128, de 2008, do CFC o objetivo da Contabilidade Aplicada ao Setor Público é fornecer aos usuários informações sobre os resultados alcançados e os aspectos de natureza orçamentária, econômica, financeira e física do patrimônio da entidade do setor público e suas mutações, em apoio ao processo de tomada de decisão; a adequada prestação de contas; e o necessário suporte para a instrumentalização do controle social. Portanto, esta nova contabilidade deve ir além dos registros das mutações e servir de fonte de informação e de prestação de contas para o efetivo controle social.

\subsection{Contabilidade Pública}


A contabilidade pública é o ramo da ciência contábil que tem por objetivo captar, registrar, resumir e interpretar os fenômenos que afetam as situações orçamentárias, financeiras e patrimoniais das entidades governamentais (MAGALHÃES et al. 2005). Para Lima e Castro (2007, p. 1), a contabilidade pública é:

o ramo de conhecimento especializado da Ciência Contábil que aplica no processo gerador de informações os conceitos, princípios e normas contábeis na gestão patrimonial de uma entidade governamental.

No mesmo sentido, Kashiwakura (1997) afirma que ela pode ser entendida na concepção de um sistema "que visa gerar informações sobre as transações financeiras das entidades governamentais e seus efeitos sobre a estrutura do patrimônio [...]”. Kashiwakura afirma que ela deve servir aos gestores com informações para tomada de decisões de natureza econômica, social, financeira e administrativa. Com o avanço da legislação e com o evidente processo de convergência por que passa a Contabilidade, também este ramo da ciência contábil teve de se aprimorar, agindo de forma assertiva no cumprimento de seus princípios e desenvolvendo meios de atender a nova realidade agora imposta.

Percebe-se o avanço da contabilidade pública no país, principalmente, com o advento da LRF e, mais recentemente, com a criação das NBCASP e, também, com a edição, em 2011, do Manual de Contabilidade Aplicado ao Setor Público - MCASP (BRASIL, 2011). Na atualidade, a contabilidade pública deve servir de meio para o efetivo controle da sociedade, servindo de base para a geração de informações que permitam o acompanhamento pelo conjunto da sociedade das contas públicas e da gestão do seu patrimônio.

Para Conto, Galante e Oenning (2008, p.4), este ramo da ciência contábil tem ainda entre suas atribuições: (1) registrar a previsão das receitas e a fixação das despesas estabelecidas no orçamento público; (2) escriturar a execução orçamentária; (3) comparar a previsão e a realização das receitas e despesas; (4) controlar operações de crédito; (5) controlar a dívida ativa; (6) controlar os créditos e obrigações; (7) demonstrar as variações e o valor do patrimônio da entidade. Notadamente, este entendimento está voltado para os aspectos orçamentários com a previsão da receita e a fixação das despesas e a escrituração da execução orçamentária e também para o controle do patrimônio de seus bens, direitos e obrigações e suas variações.

Todavia, a contabilidade pública brasileira passou recentemente por mudanças que tentam efetivar a já antiga necessidade de controle de custos e ampliar seu horizonte de análise, observação e registro, para que ela seja fonte de informações mais precisas para a tomada de decisão e para o controle social. Neste sentido, surgiram as NBCASP. 


\subsection{Normas Contábeis do Setor Público - NBCASP}

As recentes alterações na contabilidade pública brasileira, em sua origem, decorrem do movimento de convergência aos padrões internacionais formalizadas pelo Internacional Accounting Standards Board - IASB como forma de melhorar a informação. Neste sentido, Morais e Platt Netto (2011) afirmam que a convergência inicialmente estava vinculada ao setor privado e foi estendida ao setor público visando à possibilidade de comparar resultados obtidos pelos entes governamentais e a melhora da qualidade da informação e da evidenciação contábil.Com este enfoque, as NBCASP foram constituídas por meio de um conjunto de dez resoluções, conforme consta do Quadro 6.

Quadro 6 - Aspectos Relevantes da NBCASP

\begin{tabular}{|c|c|}
\hline Resolução & \\
\hline $\begin{array}{l}\text { Resolução CFC } n^{\circ} 1.128 / 08 \text {, aprova } \\
\text { a NBTC } 16.1 \text { - Conceito, Objetivo e } \\
\text { Campo de Aplicação }\end{array}$ & $\begin{array}{l}\text { Conceitua a contabilidade pública como ramo da ciência contábil, } \\
\text { delimita como objetivo o patrimônio público e caracteriza como sua } \\
\text { função social evidenciar informações de natureza econômica, } \\
\text { orçamentária, financeira e física do patrimônio da entidade. }\end{array}$ \\
\hline $\begin{array}{l}\text { Resolução CFC } \mathrm{n}^{\circ} 1.129 / 08 \text {, aprova } \\
\text { a NBTC } 16.2-\text { Patrimônio e } \\
\text { Sistemas Contábeis }\end{array}$ & $\begin{array}{l}\text { Divide o Sistema Contábil Público em cinco Subsistemas de } \\
\text { Informações Contábeis: (1) Orçamentário; (2) Financeiro; (3) } \\
\text { Patrimonial; (4) Custos; (5) Compensação; }\end{array}$ \\
\hline $\begin{array}{l}\text { Resolução CFC } \mathrm{n}^{\circ} 1.130 / 08 \text {, aprova } \\
\text { a NBTC } 16.3 \text { - Planejamento e seus } \\
\text { Instrumentos sob o Enfoque } \\
\text { Contábil }\end{array}$ & $\begin{array}{l}\text { Estabelece as bases para as normas de controle contábil sobre o } \\
\text { planejamento das entidades do setor público. Amplia o controle } \\
\text { contábil sobre os instrumentos de planejamento. Objetiva ainda } \\
\text { acompanhar o cumprimento das metas estratégicas contidas no } \\
\text { PPA. }\end{array}$ \\
\hline $\begin{array}{l}\text { Resolução CFC } n^{\circ} 1.131 / 08 \text {, aprova } \\
\text { a NBTC } 16.4 \text { - Transações no Setor } \\
\text { Público }\end{array}$ & $\begin{array}{l}\text { Caracteriza como transações no Setor Público os atos e fatos que } \\
\text { promovem alterações qualitativas e quantitativas, efetivas ou } \\
\text { potenciais, no patrimônio da entidade pública. Separa as transações } \\
\text { em econômica, financeira e administrativa. }\end{array}$ \\
\hline $\begin{array}{l}\text { Resolução CFC n }{ }^{\circ} 1.132 / 08 \text {, a } \\
\text { a NBTC } 16.5 \text { - Registro Contá }\end{array}$ & $\begin{array}{l}\text { u os critérios para o registro contábil dos atos e fatos que } \\
\text { u possam vir afetar o patrimônio público, trata da estrutura } \\
\text { de contas contábil e abre a possibilidade de escrituração } \\
\text { eletrônica. }\end{array}$ \\
\hline $\begin{array}{l}\text { Resolução CFC n }{ }^{\circ} 1.133 / 08 \text {, aprova } \\
\text { a NBTC } 16.6-\text { Demonstrações } \\
\text { Contábeis }\end{array}$ & $\begin{array}{l}\text { Estabelece os demonstrativos que devem ser divulgados pela } \\
\text { contabilidade pública: (1) Balanço Patrimonial; (2) Balanço } \\
\text { Orçamentário; (3) Balanço Financeiro; (4) Demonstração das } \\
\text { Variações Patrimoniais; (5) Demonstração do Fluxo de Caixa; (6) } \\
\text { Demonstração do Resultado Econômico. }\end{array}$ \\
\hline $\begin{array}{l}\text { Resolução CFC no } 1.134 / 08 \text {, aprova } \\
\text { a NBTC } 16.7 \text { - Consolidação das } \\
\text { Demonstrações Contábeis }\end{array}$ & $\begin{array}{l}\text { Conceitua a Unidade Contábil Consolidada como soma da } \\
\text { agregação de saldos ou grupos de duas ou mais unidades contábeis } \\
\text { originárias. Esta consolidação objetiva o conhecimento e a } \\
\text { disponibilização de macroagregados do setor público, a visão global } \\
\text { do resultado e a instrumentalização. }\end{array}$ \\
\hline $\begin{array}{l}\text { Resolução CFC n }{ }^{\circ} 1.135 / 08 \text {, aprova } \\
\text { a NBTC } 16.8 \text { - Controle Interno }\end{array}$ & $\begin{array}{l}\text { Estabelece aspectos do controle interno aplicável às entidades } \\
\text { públicas, objetivando garantir razoável grau de eficiência e eficácia } \\
\text { do sistema de informação contábil. }\end{array}$ \\
\hline $\begin{array}{l}\text { Resolução CFC no } 1.136 / 08 \text {, aprova } \\
\text { a NBTC } 16.9-\text { Depreciação, } \\
\text { Amortização e Exaustão }\end{array}$ & $\begin{array}{l}\text { A norma inova na medida em que estabelece que o valor da } \\
\text { depreciação, amortização e exaustão deve ser apurado, } \\
\text { mensalmente, algo que não era realizado até o momento no âmbito } \\
\text { do setor público. }\end{array}$ \\
\hline
\end{tabular}




\begin{tabular}{|c|c|}
\hline $\begin{array}{l}\text { Resolução CFC n }{ }^{\circ} 1.137 / 08 \text {, aprova } \\
\text { a NBTC } 16.10-\text { Avaliação e } \\
\text { Mensuração de Ativos e Passivos } \\
\text { em Entidades do Setor Público }\end{array}$ & $\begin{array}{l}\text { Cria critérios e procedimentos para a avaliação e mensuração de } \\
\text { ativos e passivos integrantes do patrimônio público das entidades } \\
\text { governamentais, prevê a contabilização no Ativo Permanente dos } \\
\text { Bens de Uso Comum algo que não era contabilizado anteriormente. }\end{array}$ \\
\hline $\begin{array}{l}\text { Resolução CFC n }{ }^{\circ} \text { 1.366/11, aprova } \\
\text { a NBTC } 16.11 \text { - Sistema de } \\
\text { Informação de Custos do Setor }\end{array}$ & $\begin{array}{l}\text { Estabelece a conceituação, o objeto, os objetivos e as regras básicas } \\
\text { para mensuração e evidenciação dos custos no setor público. }\end{array}$ \\
\hline
\end{tabular}

Fonte: Elaborado com base em CFC (2008) e Darós e Pereira (2009)

Até o advento das novas normas não existia um conjunto de normativos que regrassem especificamente os diversos aspectos da contabilidade pública nacional, gerando muitas vezes interpretações equivocadas e desiguais em uma mesma Unidade Federativa. Apesar da Lei 4.320/64 trazer aspectos como quais as demonstrações (balanço patrimonial, balanço financeiro, balanço orçamentário e as demonstrações das variações patrimoniais) que caberiam à contabilidade pública evidenciar, em outros aspectos, foi incipiente. Dentre estes aspectos, destaca-se a falta de um detalhamento de como deveria funcionar a apuração de custos, bem como a classificação de ativos e passivos não tratados adequadamente na lei.

Um aspecto inovador das NBCASP que está alinhado com as características da Nova Gestão Pública e, ainda, com o que preceitua a LRF, é a criação do Subsistema de Custos SIC destinado, segundo a Resolução $\mathrm{n}^{\circ} 1.129 / 2008$, a registrar, processar e evidenciar os custos "dos bens e serviços, produzidos e ofertados à sociedade pela entidade pública" e a especificar que a contabilidade deve apoiar, por meio destes subsistemas, a administração pública nos seguintes aspectos: (a) desempenho da unidade contábil no cumprimento da sua missão; (b) avaliação dos resultados obtidos na execução dos programas de trabalho com relação à economicidade, à eficiência, à eficácia e à efetividade; (c) avaliação das metas estabelecidas pelo planejamento; (d) avaliação dos riscos e das contingências.

Com efeito, passa agora a contabilidade pública brasileira a ter a possibilidade de que os órgãos públicos implantem um sistema de contas específicas para o controle dos custos tal como existe para as contas patrimoniais e orçamentárias. As Normas também inovaram quanto ao conjunto de demonstrações que devem ser evidenciados pelos órgãos, inserindo além do Balanço Patrimonial, Balanço Orçamentário, Balanço Financeiro e da Demonstração das Variações Patrimoniais e do Resultado Econômico e o Demonstração do Fluxo de Caixa.

As relevantes alterações trazidas pelas normas fazem com que a contabilidade pública brasileira avance de uma situação onde o foco era o orçamento público para uma visão de gestão e controle do patrimônio público mais efetivo (CASTRO, 2011), pois ampliam a 
possibilidade de gerenciamento e controle com novos subsistemas, novos critérios e demonstrações

\title{
3 METODOLOGIA
}

Para a classificação desta pesquisa utilizou-se o estudo de Raupp e Beuren (2003). A pesquisa é classificada quanto aos objetivo como exploratório em razão dos poucos estudos sobre o tema da impacto entre as reformas da administração pública no Brasil e o processo mudança da contabilidade pública. Conforme Raupp e Beuren (2003, p. 80) a pesquisa exploratória "ocorre quando há pouco conhecimento sobre a temática a ser abordada".

Quanto aos procedimento a pesquisa é classificada como bibliográfica. A pesquisa foi feita na plataforma de busca Google Acadêmico identificando somente estudos que tivessem sido publicados em Congressos ou Revistas Científica.

Quanto a abordagem do problema é classificada como qualitativa. A pesquisa qualitativa segundo Raupp e Beuren (2003) diferencia-se da quantitativa por esta empregar métodos e técnicas estatística, elementos a que não recorre a pesquisa qualitativa. Segundo os mesmo autores a pesquisa qualitativa permite uma análise mais profunda em relação ao fenômeno estudado visando identificar características do fenômeno e não só quantificá-los.

\section{ANÁLISE E DISCUSSÃO DOS RESULTADOS}

\subsection{Características da Padronização da Norma}

De um modo geral, historicamente, sempre houve no Brasil uma divisão da Contabilidade - entre Pública e Privada, também chamadas, respectivamente, de Governamental e Comercial, com regras específicas e formação acadêmica direcionada para cada ramo. Para Castro (2011, p. 100), este cenário está em fase de modificação:

\begin{abstract}
A edição das Normas Brasileira de Contabilidade Aplicadas ao Setor Público (NBCASP) destacando a importância dos aspectos patrimoniais no setor público, sem perder de vista as peculiaridades dos aspectos orçamentários, complementadas pelas alterações na estrutura do plano de contas do Setor Público, na reestruturação dos Anexos da Lei n. 4320/64 e nas mudanças da Lei n. ${ }^{\circ}$ 6404/76 do setor privado, pelas Leis $n^{\circ} 11.638 / 07$ e 11.941/09 estão evidenciando aproximação entre as duas contabilidades e, ambas, em busca da convergência com a normas internacionais.
\end{abstract}

Percebe-se a tendência da harmonização entre as normas de contabilidade como sendo uma característica atual dos novos modelos de negócio e de acesso à informação. No Brasil, as primeiras ações em prol da harmonização da contabilidade pública foram realizadas no 
âmbito do Comitê Gestor de Convergência; esta harmonização também abrangeu a contabilidade pública (CASTRO, 2011).

Neste sentido, a harmonização tem como centro a mudança do enfoque da contabilidade pública que era eminentemente voltada para o controle orçamentário, passando a ser uma contabilidade pública patrimonial, com a adoção do regime de competência para as receitas e despesas públicas (DARÓS e PEREIRA, 2009).

Darós e Pereira (2009, p. 11) ainda consideram que as novas normas "são um instrumento para elevar a eficácia e efetividade das Leis quanto aos objetivos de promover o planejamento, a transparência e responsabilidade da gestão fiscal”. Castro (2011) vai mais longe ao analisar as mudanças na contabilidade pública brasileira e afirma que, no conjunto, as novas normas possuem aspectos favoráveis e desfavoráveis, conforme apresentado no Quadro 7.

Quadro 7 - Fatores Favoráveis e Desfavoráveis da NBCASP

\begin{tabular}{|l|l|}
\hline \multirow{5}{*}{$\begin{array}{l}\text { Fatores } \\
\text { Favoráveis }\end{array}$} & $\begin{array}{l}\text { 1) Uniformidade de procedimentos contábeis nos aspectos patrimoniais entre o } \\
\text { setor público e privado; }\end{array}$ \\
\hline & 2) Aderência a conceitos e regras internacionais; \\
\hline 3) Plano de Contas Único; \\
\hline $\begin{array}{l}\text { 4) Ganho de governabilidade e de economicidade para os cofres públicos em razão } \\
\text { da concorrência entre fornecedores de sistemas informatizados de contabilidade } \\
\text { reduzindo o custo da contratação; }\end{array}$ \\
\hline & $\begin{array}{l}\text { 5) Melhoria no ensino da contabilidade pública pela padronização de conceitos } \\
\text { patrimoniais }\end{array}$ \\
\hline \multirow{5}{*}{$\begin{array}{l}\text { Fatores } \\
\text { Desfavoráveis }\end{array}$} & $\begin{array}{l}\text { 1) Separação dos sistemas contábeis, dos financeiros e orçamentários como } \\
\text { acontecia antes; }\end{array}$ \\
\hline & $\begin{array}{l}\text { 2) Dificuldade de entendimento dos usuários e interessados pelas informações } \\
\text { devido à multiplicidade de expressões e conceitos para termos semelhantes; }\end{array}$ \\
\hline & $\begin{array}{l}\text { 3) Falta de interesse pelas informações patrimoniais, com redução na importância } \\
\text { da Contabilidade e dos contabilistas; }\end{array}$ \\
\hline & $\begin{array}{l}\text { 4) Dificuldade técnica para elaborar o Balanço Financeiro e a Demonstração do } \\
\text { Fluxo de Caixa com o fim dos registros contábeis no sistema financeiro. }\end{array}$ \\
\hline
\end{tabular}

Fonte: Elaborado com base em Castro (2011).

Os aspectos favoráveis trazidos pela norma reportam ao controle do patrimônio público. Neste quesito, houve um avanço da contabilidade para um novo patamar, ultrapassando os limites do mero controle orçamentário. Outro elemento favorável é a convergência para um padrão internacional, além da criação de plano de contas único que facilitará a comparação regional e, quem sabe, no futuro, entre países.

Os pontos desfavoráveis trazidos por Castro (2011) remetem essencialmente à falta de cultura dos usuários no uso de informações patrimoniais e ao nível de conhecimento dos usuários sobre as informações contábeis e as questões formais, como as dificuldades em 
elaborar a demonstração de fluxo de caixa e o balanço financeiro. Porém, percebe-se que estas dificuldades podem ser vencidas com uma qualificação dos usuários e geradores da informação contábil, parecendo não uma limitação da nova norma, mas sim, uma limitação da qualidade ou qualificação dos usuários, uma vez que as dificuldades existentes em razão do número excessivo de termos e expressões semelhantes, ao longo do tempo, podem ser vencidas com a qualificação e o próprio uso recorrente das normas. Castro (2011), ainda elencando outros aspectos negativos da norma voltados ao exercício da profissão de contador, em órgãos públicos, salienta que ela pode acarretar em perda de espaço, alegando que o controle do orçamento e das finanças pode migrar para profissionais de administração ou de economia.

\subsection{Impacto das reformas da gestão pública na nova contabilidade governamental}

Como já apresentado as reformas na contabilidade pública estão centradas em criar um conjunto de dispositivos que não só se alinhem as regras internacionais as IPSAS, para que no futuro permita sua maior harmonização, mas avance de uma contabilidade meramente orçamental para uma contabilidade patrimonial.

As normas apresentam que a CASP é o ramo da ciência contábil que aplica, no processo gerador de informações, os Princípios de Contabilidade e as normas contábeis direcionados ao controle patrimonial de entidades do setor público (CFC, 2013).

O objetivo da nova CASP é fornecer aos usuários informações sobre os resultados alcançados e os aspectos de natureza orçamentária, econômica, financeira e física do patrimônio da entidade do setor público e suas mutações, em apoio ao processo de tomada de decisão; a adequada prestação de contas; e o necessário suporte para a instrumentalização do controle social. Percebe-se nesse sentido o novo contexto que ela está inserida, devendo ter como foco atender objetivos que não são meramente orçamentais ou patrimoniais, mas de apoio a gestão, processo decisório, transparência e controle social. A Figura 1 apresenta o mapeamento da relação entre os objetivos da CASP e os preceitos da NGP. 


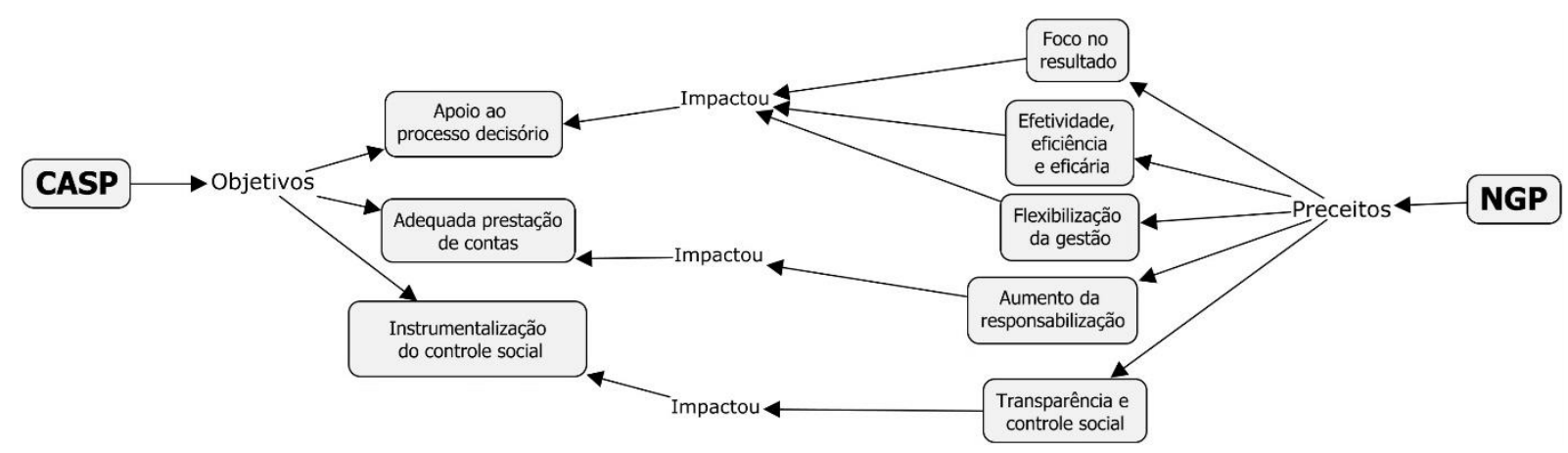

Figura 1 - Mapeamento da relação entre CASP e NGP

Fonte: Elaborado pelos autores (2014).

Os preceitos da nova gestão pública apresentados na literatura por Bliska e Vicente (2001), Rezende (2002), Sano e Abrucio (2008), Lima (2009) como o foco no resultado, na efetividade, eficiência e eficácia, uma maior flexibilidade da gestão, a busca pela maior responsabilização, transparência e controle social, podem ser relacionado aos objetivos da CASP.

Um dos objetivos da CASP é apoiar o processo decisório, pode-se inferior que este objetivo tem relação direta com os preceitos da NGP pois esta tem entre seus fundamentos uma administração voltada para o resultado para a efetividade, eficiência e eficácia, uma maior flexibilidade da gestão. Assim uma gestão mais flexível a mudanças, preocupada mais com resultados do que com processos

A contabilidade incorporou entre seus objetivos, conforme próprio texto normativo, o apoio ao processo de decisão, quando o gestor decide corretamente diminui o risco, aumentando sua chance de acerto, na buscar de tomar decisões corretas que resultem na melhor utilização dos recursos públicos. As principias normas vinculadas a este aspectos são apresentadas no Quadro 08.

Quadro 8 - Vinculação entre as normas e a NGP sob o enfoque gerencial

\begin{tabular}{|c|l|}
\hline NBCASP & \multicolumn{1}{c|}{ Fator de impacto } \\
\hline $\begin{array}{c}\text { NBTC 16.3 - } \\
\text { Planejamento e seus } \\
\text { Instrumentos sob o Enfoque } \\
\text { Contábil }\end{array}$ & $\begin{array}{l}\text { Este norma por ter como foco estabelecer as bases para o controle contábil } \\
\text { sobre o planejamento das entidades do setor público, permite ampliar o } \\
\text { controle contábil sobre os instrumentos de planejamento apoiando o } \\
\text { processo decisório. }\end{array}$ \\
\hline NBTC 16.8 - Controle Interno & $\begin{array}{l}\text { Estabelece aspectos do controle interno aplicável às entidades públicas, } \\
\text { objetivando garantir razoável grau de eficiência e eficácia do sistema de } \\
\text { informação contábil, como resultado melhora a informação para a tomada } \\
\text { de decisão. }\end{array}$ \\
\hline $\begin{array}{c}\text { NBTC 16.11 - Sistema de } \\
\text { Informação de Custos do Setor } \\
\text { Público }\end{array}$ & $\begin{array}{l}\text { Estabelece a conceituação, o objeto, os objetivos e as regras básicas para } \\
\text { o controle dos custos, aumenta a eficiência na decisão de alocação e } \\
\text { recursos e na redução de gastos. }\end{array}$ \\
\hline
\end{tabular}

Fonte: Elaborado pelos autores (2014)

Volume 3, Número 6

Revista UNEMAT de Contabilidade

Jul./Dez. 2014

UNEMAT 
A NGP prega o aumento da responsabilização por parte dos gestores, espera-se que estes prestem contas de seus atos de gestão, algo que está vinculado a um dos novos objetivos da CASP que é realizar ou apoiar a efetivação da adequada prestação de contas. A responsabilização aqui referida vai além da prestação de contas, especificada em outro objetivo. Deve ser percebida como relacionada ao atendimento das demandas sociais, os desejos da sociedade e suas necessidades por meio da prestação de serviços públicos de qualidade, assim deve o gestor atuar, otimizando os recursos públicos e ampliando a qualidade e o número de serviços ofertados, assim a administração pública deve gerar resultado, retornando para a sociedade sua taxa de impostos. A responsabilização dos gestores públicos por melhores resultados está no centro da aplicação da NGP. Pode-se inferir que a contabilidade também incorporou esta realidade e a traduziu formalmente em seu objetivo quando apresentou de forma expressa "a adequada prestação de contas". As principais normas vinculadas a este objetivo apresentadas no Quadro 09.

Quadro 09 - Vinculação entre as normas e a NGP sob o enfoque da adequada prestação de contas

\begin{tabular}{|l|l|}
\hline NBCASP & Fator de impacto \\
\hline Resolução CFC no $1.133 / 08$, aprova & $\begin{array}{l}\text { Estabelece os demonstrativos que devem ser divulgados pela } \\
\text { contabilidade pública: (1) Balanço Patrimonial; (2) Balanço }\end{array}$ \\
$\begin{array}{l}\text { Orçamentário; (3) Balanço Financeiro; (4) Demonstração das } \\
\text { a NBTC 16.6 - Demonstrações }\end{array}$ & $\begin{array}{l}\text { Variações Patrimoniais; (5) Demonstração do Fluxo de Caixa; (6) } \\
\text { Contábeis }\end{array}$ \\
& $\begin{array}{l}\text { Demonstração do Resultado Econômico. Este conjunto de } \\
\text { demonstrativos deve apoiar os gestores a prestar contas de seus atos } \\
\text { a entidades de controle e sociedade; }\end{array}$ \\
\hline
\end{tabular}

Fonte: Elaborado pelos autores (2014)

A NGP tem entre seus preceitos a aumento da transparência e o incentivo ao controle social do setor público. Para a NGP a administração pública deve adotar mecanismos que garantam a transparência e publicidade dos atos de gestão pública, tanto financeiros como não financeiros. Também deve incentivar que a sociedade exerça o controle social e ocupe os espaços de participação e controle atribuídos a ela. A contabilidade pública atual estabelece como já referido entre seus objetivos o apoio a instrumentalização do controle social. O Quadro 10 apresenta as NBCASP que atendem a este objetivo de forma mais direta.

Quadro 10 - Vinculação das normas a NGP em a instrumentalização do controle social

\begin{tabular}{|c|l|}
\hline NBCASP & \multicolumn{1}{c|}{ Fator de impacto } \\
\hline $\begin{array}{c}\text { NBTC 16.6 - Demonstrações } \\
\text { Contábeis }\end{array}$ & $\begin{array}{l}\text { Ao estabelecer os demonstrativos aplicados ao segmento público tenta } \\
\text { apoiar o controle social. }\end{array}$ \\
\hline $\begin{array}{c}\text { NBTC 16.7 - Consolidação das } \\
\text { Demonstrações Contábeis }\end{array}$ & $\begin{array}{l}\text { Introduz uma visão global das contas públicas o que permite comparações } \\
\text { e a fiscalização do setor. }\end{array}$ \\
\hline NBTC 16.8 - Controle Interno & $\begin{array}{l}\text { Garante o fidedignidade das demonstrações contábeis, que permite ao } \\
\text { controle social ter a possibilidade de garantia que as informações estão } \\
\text { corretas. }\end{array}$ \\
\hline $\begin{array}{c}\text { NBTC 16.11 - Sistema de } \\
\text { Informação de Custos do Setor }\end{array}$ & $\begin{array}{l}\text { O sistema de custos evidencia como os recursos públicos estão sendo } \\
\text { aplicados para a sociedade controlar a eficiência do gasto público. }\end{array}$ \\
\hline
\end{tabular}


\begin{tabular}{c|c} 
Público & \\
Fonte: Elaborado pelos autores (2014)
\end{tabular}

O controle social para ser exercido pela sociedade precisa de informações. Estas informações devem vir de um sistema contábil confiável e seguro, mas além disso a contabilidade deve promover uma linguagem adequada para que as pessoas possam interpretar as informações e exercer com acessibilidade o controle social.

\section{CONCLUSÃO}

O estudo teve como objetivo descrever como as reformas do setor público motivaram as mudanças contábeis, apoiadas em um processo de convergência internacional das normas. Para tal foi apresentado um revisão da literatura sobre as fases da administração pública brasileira, nomeadamente, patrimonialismo, a burocrática e a NGP. Durante a revisão percebeu-se que as reformas não são um processo de ruptura e sim um processo de ajustamento, inovação e incorporação a nova realidade social e econômica, na tentativa de aprimorar-se.

A NGP que tem em sua gênese incorporar, não só práticas, mas um modelo mais próximo do utilizado no setor privado tendo com foco a gestão por resultado, a prestação de contas e a responsabilização. Alguns preceitos da NGP podem ser identificados como fatores que foram incorporado aos novos objetivos da contabilidade pública brasileira e ao seu conjunto de normas.

Este impacto fica evidente quando se compara os aspectos fundamentais da NGP apresentado por Sano e Abrucio (2008) com os objetivos da contabilidade pública, com vinculação direta entre a administração voltada para o resultado e ao apoio que a contabilidade deve dar ao processo de tomada de decisão e a flexibilização da gestão e responsabilização com a adequada prestação de contas; e suporte para a instrumentalização do controle social. Este relação entre os preceitos da NGP, os objetivos da CASP foi tratada na Figura 01.

É possível ainda, concluir que existe uma relação direta entre os objetivos, decorrentes de preceitos da NGP e a conteúdo das NBCASP que é representado pela mapa conceitual da relação, Figura 02. 


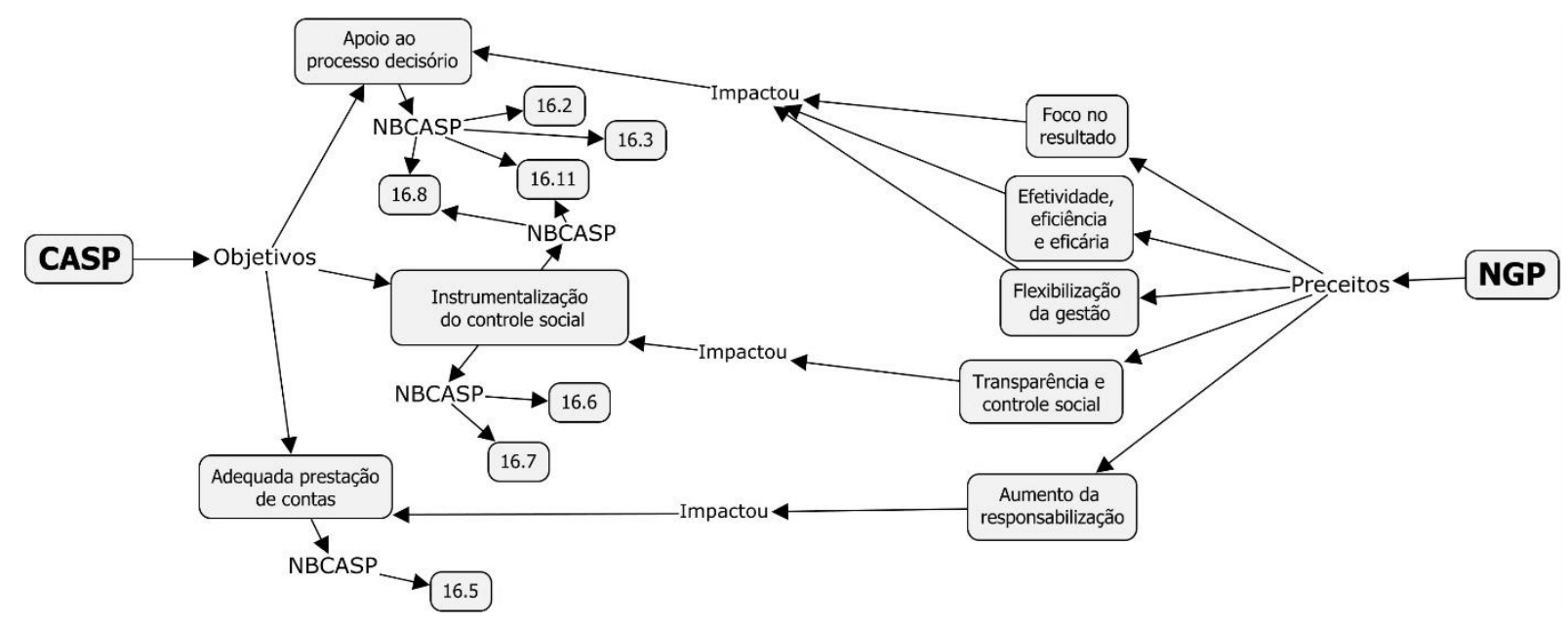

Figura 2 - Mapa de relação entre preceitos da NGP, objetivos NBCASP e normas editadas

Fonte: Elaborado pelos autores (2014).

Conclui-se, como pode-se observar na figura 02 que o objetivo relacionado ao apoio ao processo decisório esta materializado pelas NBCASP 16.3 e 16.8 e 16.11, conforme detalhado no Quadro 08. O objetivo relacionado a instrumentalização do controle social tem relação direta com as normas 16.6, 16.7 e 16.8, conforme detalhando no Quadro 09. O objetivo relacionado com a adequada prestação de contas tem relação direta com a NBCASP 16.5 .

Outro impacto de grande significado da NGP nas NBCASP foi a criação de um novo subsistema contábil destinado exclusivamente ao controle de custos, alinhando-se assim uma prática forte do setor privado (gestão de custos) a realidade do setor público onde praticamente inexiste referido na NBCASP 16.11. Também elementos como depreciação, amortização e exaustão tornam-se práticas contábeis vinculadas as já existentes no setor privado.

Recomenda-se empíricos que explorem esta vinculação que permitem evidenciar quais inovações trazidas pelas NBCASP são decorrentes do impacto da NGP na realidade contábil brasileira.

\section{REFERÊNCIAS}

ABRUCIO, Fernando Luiz. Trajetória recente da gestão pública brasileira: um balanço crítico e a renovação da agenda de reformas. Revista de Administração Pública, Ed. Comemorativa, pp. 67-86, 2007.

BLISKA, Anita V.; VICENTE, Ernesto Fernando Rodrigues. A Administração Pública Gerencial. In: CONGRESSO INTERNACIONAL DE COSTOS, 7, 2001, Leon, Anais 
eletrônicos. Leon/Espanha: 2001. Disponível em: <http://www.intercostos.org/por/tp_congresos.php?id=654>. Acesso em 20 dez. 2013.

RAUPP, F. M., BEUREN, I. M. (2003). Metodologia da pesquisa aplicável às ciências sociais. Como elaborar trabalhos monográficos em contabilidade: teoria e prática, 3, 7697.

BRASIL. Constituição Federal (1988), art. 225. Disponível em: <tp://www.planalto.gov.br/ccivil_03/Constituicao/Constituiçao.htm>. Acesso em: 16 mai. 2012.

Lei Complementar $\mathbf{n}^{\mathbf{0}}$ 101, DE 4 DE MAIO DE 2000 - Lei de Responsabilidade Fiscal_LRF - DOU de 05.05.2000.

. Lei Complementar $n^{\circ}$ 131, DE 27 DE MAIO DE 2009 - Lei da Transparência DOU de 28.05.2009.

Plano Diretor da Reforma do Aparelho do Estado. Presidência da República, Câmara da Reforma do Aparelho do Estado, Brasília, 1995.

Secretaria do Tesouro Nacional. Manual de Contabilidade Aplicado ao Setor Público: aplicado à União, Estados, Distrito Federal e Municípios/Ministério da Fazenda, STN. 4. ed. Brasília: STN, Coordenação- Geral de Normas de Contabilidade Aplicadas à Federação, 2011. 819 p.

, Secretaria do Tesouro Nacional, Portaria Conjunta STN/SOF n. 3 de 2008 - Aprova o Manual de Despesa Pública Nacional, $1^{\circ}$ ed. 2008.

BRESSER-PEREIRA, Luiz Carlos. Revista do Serviço Público, 47(1) janeiro/abril 1996. Trabalho apresentado ao seminário sobre Reforma do Estado na América Latina organizado pelo Ministério da Administração Federal e Reforma do Estado e patrocinado pelo Banco Interamericano de Desenvolvimento (Brasília, maio de 1996).

CAMPANTE, Rubens G. O Patrimonialismo em Faoro e Weber e a Sociologia Brasileira. In: Dados - Revista de Ciências Sociais, n. 1, p. 153-193, 2003.

CASTRO, Domingos Poubel de. Auditoria, contabilidade e controle interno no setor público: integração das áreas do ciclo de gestão 4. ed. São Paulo: Atlas, 568 p. 2011.

CFC - Conselho Federal de Contabilidade. Resolução CFC no 1.128/08. Disponível em: <http://www.cfc.org.br/sisweb/sre/Default.aspx>. Acesso em: 13 jan. 2013.

Resolução CFC $\quad \mathbf{n}^{\circ} \quad \mathbf{1 . 1 2 9 / 0 8}$ Disponível em: <http://www.cfc.org.br/sisweb/sre/Default.aspx>. Acesso em: 12 jan. 2012.

- Resolução $\quad$ CFC $\quad \mathbf{n}^{\mathbf{0}}$ 1.130/08. Disponível em: <http://www.cfc.org.br/sisweb/sre/Default.aspx>. Acesso em: 12 jan. 2012.

\begin{tabular}{lr}
\hline Volume 3, Número 6 & Revista UNEMAT de Contabilidade \\
Jul./Dez. 2014 & UNEMAT
\end{tabular}


- Resolução $\quad$ CFC $\quad \mathbf{n}^{\mathbf{0}}$ 1.131/08. Disponível em:

<http://www.cfc.org.br/sisweb/sre/Default.aspx>. Acesso em: 12 jan. 2012.

Resolução $\quad$ CFC $\quad \mathbf{n}^{\mathbf{1}} \quad \mathbf{1 . 1 3 2 / 0 8}$ Disponível em:

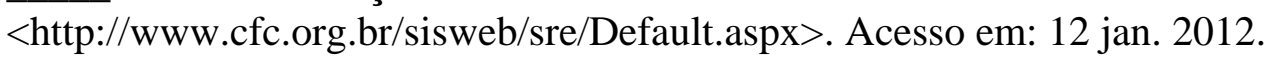

- Resolução $\quad$ CFC $\quad \mathbf{n}^{\mathbf{0}} \quad \mathbf{1 . 1 3 3 / 0 8}$. Disponível em:

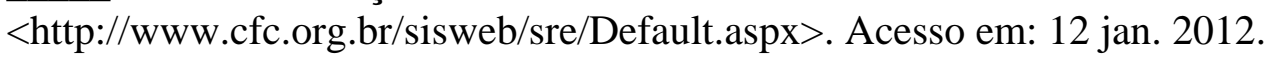

- Resolução $\quad$ CFC $\quad \mathbf{n}^{\mathbf{0}} \quad \mathbf{1 . 1 3 4 / 0 8} \quad$ Disponível $\quad$ em:

<http://www.cfc.org.br/sisweb/sre/Default.aspx>. Acesso em: 12 jan. 20132.

Resolução $\quad$ CFC $\quad \mathbf{n}^{\mathbf{1}} \quad \mathbf{1 . 1 3 5 / 0 8}$ Disponível em:

<http://www.cfc.org.br/sisweb/sre/Default.aspx>. Acesso em: 12 jan. 2013.

Resolução CFC $\mathbf{n}^{\mathbf{1}}$ 1.136/08. Disponível em:

<http://www.cfc.org.br/sisweb/sre/Default.aspx>. Acesso em: 12 jan. 2013.

$\begin{array}{llllll}\text {. Resolução } & \text { CFC } & \mathbf{n}^{0} & \mathbf{1 . 1 3 7 / 0 8} & \text { Disponível em: }\end{array}$

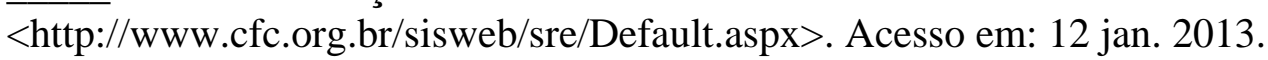

CFC - Conselho Federal de Contabilidade. Resolução CFC No 1.366/11. Disponível em: <http://www.cfc.org.br/sisweb/sre/Default.aspx>. Acesso em: 13 jan. 2013.

CHRISTEnsen, T.; LAEGRID, P. (eds) (2001). In: New Public Management - The transformation of Ideas and Practice (Aldershot, Ashgate).

CONTO, Angelita Adriane de; GALANTE, Celso; OENNING, Vilmar. Mensuração da eficácia na gestão de recursos públicos. In: Congresso Brasileiro de Contabilidade 18, CFC, Gramado, RS, 2008.

COSTA, Frederico Lustosa da. Brasil: 200 anos de Estado; 200 anos de administração pública; 200 anos de reformas. Revista da Administração, vol.42, n.5, pp. 829-874. 2008.

DARÓS, Leandro Luís; PEREIRA, Adriano de Souza. Análise das normas brasileiras de contabilidade aplicadas ao setor público - NBCASP: mudanças e desafios para a contabilidade pública. In. Congresso USP de Iniciação Científica, 6, 2009. Anais... São Paulo: USP, 2009. Disponível em: 〈http://www.congressousp.fipecafi.org/artigos92009/467.pdf>. Acesso em: 02

dez. 2009.

FÁBIAN, Adrián. New public management and what comes after. Current Issues of Business and Law, v. 5. Escola Internacional de Direito e Negócios, Vilnius, Lituania, p. 4156, 2010.

GIACOMO, W. A. D. O new public management no Canadá e a gestão pública contemporânea. Interfaces Brasil/Canadá, n. 5, 2005. 
GRAEF, A. Origens e fundamentos da carreira de Gestor Governamental. Revista de Políticas Públicas e Gestão Governamental Vol. 9 - No1 Jan/Jun 2010.

HOOD, Christopher, The new public management in the 1980s: variations on a theme. Accounting, Organizations and Society, v. 20 n. 2/3 p. 93-109, Elsevier Science Ltd. Grâ Betania, 1995.

KASHIWAKURA, Helder Kiyoshi. Controle e Avaliação da Execução Orçamentária. Brasília: ESAF, 1997.

LIMA, Diana Vaz, CASTRO, Róbison Gonçalves de. Contabilidade Pública: Integrando União, Estados e Municípios (SIAFI e SIAFEM). 3. ed. São Paulo: Atlas, 2007.

LIMA, Paulo Daniel Barreto. Perfil contemporâneo da capacidade de gestão dos órgãos e entidades da administração pública brasileira. In: XIV Congreso Internacional del CLAD sobre la Reforma del Estado y de la Administración Pública, Salvador de Bahia, Brasil. Anais... Bahia, 27-30 oct. 2009. Disponível em: <http://www.excelenciaemgestao.org/Portals/2/documents/cneg7/anais/T11_04 15_1616.pdf>. Acesso em: 10 jun. 2012.

MAGALHÃES, Elizete Aparecida de et al. A influência da lei de responsabilidade fiscal (LRF) na tomada de decisão pelos gestores municipais. Contabilidade Vista e Revista, Belo Horizonte, v. 16, p. 9-26, 2005.

MARINI F, Caio. O contexto contemporâneo da gestão pública na América Latina. Revista do Servidor Público, ENAP, ano 53, n. 4 out./dez.+ 2002.

MARTINS, Humberto Falcão. F. A ética do patrimonialismo e a modernização da administração pública brasileira. In: MOTTA, F. C. P.; CALDAS, M. P. (Orgs.). Cultura organizacional e cultura brasileira. São Paulo: Atlas, 1997.

MEIRELLES, Hely Lopes. Direito Administrativo Brasileiro. 9. ed. São Paulo: Ed. Revista dos Tribunais, 1989.

MORAIS, Leandro de Morais; PLATT NETO, Orion Augusto. A reforma contábil promovida pelas NBCASP e o processo de convergência: implicações e perspectivas. In: ASSOCIAÇÃO NACIONAL DOS PROGRAMAS DE PÓSGRADUAÇÃO EM CIÊNCIAS CONTÁBEIS (ANPCONT), 5., 2011, Vitória (ES). Anais... Vitória: ANPCONT, 2011.

MOTTA, Paulo Roberto. A modernização da administração pública brasileira nos últimos 40 anos. Revista de Administração Pública, Edição Comemorativa, pp. 87-96, 2007.

REZENDE, José Marcelino Pinto. Financiamento da Educação no Brasil: um balanço do governo FHC. In: Educação e Sociedade, Campinas-SP, v. 23, n. 80, p. 108-135, set. 2002. 
SANO, H.; ABRUCIO, F. L. Promessas e resultados da Nova Gestão Pública no Brasil: o caso das Organizações Sociais de Saúde em São Paulo. ERA - Revista de Administração de Empresas, v. 48, p. 64-80, 2008.

SECCHI, L. Modelos organizacionais e reformas da administração pública. Revista de Administração Pública, Rio de Janeiro, FGV, 43(2):347-69, mar-abr 2009. SEGURO-BA. Anais... Porto Seguro, ABC CUSTOS, 2004. Disponível em: <http://www.escolagov.ms.gov.br/controle/ShowFile.php?id=51059>. Acesso em: 10 jul. 2012.

SOTHE, Ari; SCARPIN, Jorge Eduardo. Alteração do regime contábil no setor público: impactos nos indicadores fiscais dos municípios. In: XIII Seminário de Administração, USP, São Paulo, set. 2010. 